\title{
The Correlation between Bispectral Index Value and Glasgow Coma Scale in Isolated Head Trauma Patients
}

\author{
AHMED S. SAAD, M.Sc.; OMAR WAGIH, M.D.; INAS EL-SHAZLY, M.D.; \\ HISHAM ABU EL-DAHAB, M.D. and SAFINAZ OSMAN, M.D.
}

The Department of Anaesthesiology, Faculty of Medicine, Cairo University

\begin{abstract}
Background: We performed the current study to find out if there is a correlation between the Bispectral index value and glasgow coma scale in isolated head trauma patients undergoing surgical intervention.

Aim of the Study: Find out if bispectral index value correlate with Glasgow coma scale.

Patients and Methods: A total of 40 patients who were admitted in emergency room with isolated head trauma glasgow coma scale and bispectral index readings were recorded at time of arrival, immediately post-operative, after 3 days and 2 weeks post admission.

Results: We found that there was a strong correlation between glasgow coma scale and bispectral index readings.

Correlation coefficient was 0.956 and $p$-value $<-0.001$.

Conclusion: We conclude from this study that there is a strong correlation between glasgow coma scale and bispectral index readings.
\end{abstract}

Key Words: Traumatic head inury - Glasgow coma scale Bispectral index.

\section{Introduction}

ELECTROENCEPHALOGRAM (EEG) has been suggested to study intensity of central depression of anesthetics, and its processing has been researched to facilitate its interpretation. For this purpose extensive database of EEG readings, coming from patients undergoing different anesthetic regimens, was formed through years [1]

Electroencephalographic measures of sedation intensity were developed based on observation that in general EEG of an anesthetized patient changes from High Frequency Low Amplitude (HFLA) during consciousness to a Low Frequency High Amplitude (LFHA) when deeply anesthetized. In

Correspondence to: Dr. Ahmed S. Saad, The Department of Anaestheiology, Faculty of Medicine, Cairo University the 90 s, bispectral analysis, a type of mathematical processing commonly used in geophysics and oil prospection, was used to process the EEG signal. Bispectral Index Technology (BIS) was developed from a closed algorithm and suggested to monitor brain activity in answer to different combinations of anesthetics [1]

BIS (bispectral index) is an index empirically derived and dependent on "coherency" measurement among components of quantitative Electroencephalogram (EEG) [1]

In process of BIS calculation, the first step is acquisition of EEG signal, which is made through application of four electrodes placed on the skin surface that enable an appropriate electrical conduction with low impedance. The assembly used is the unilateral referencial with exploratory electrode in (frontal-temporal region) and reference electrode (frontpolar). This determines that the obtained EEG lineation is monocanal (left or right, according to position of frontal-temporal electrode) [2].

Digitalization is performed after acquisition and amplification of signal. The captured analog signal is presented in regular intervals (frequency expressed in $\mathrm{Hz}$ ) so that deflections of each wave are defined by a series of positive or negative concrete values dependent of the moment of data collection.

After digitalization, the signal undergoes a process of artifacts recognition. The artifacts produced by signals that exceeded dynamic limit of amplifier, like using of electric scalpel, may be identified and then are rejected, since original data can not be reconstituted other artifacts can be eliminated from contaminated signal and resulting filtered signal may be used for further analysis. 
Those types of artifacts include the ones that have frequencies superior to EEG (for instance, alternating electrical current). Other artifacts with frequency within limit of EEG waves, like ECG and the ones produced by rotating pumps are eliminated as they present regularity. Other detectable contaminants are interferences produced by stimulators of peripheral nerves as well as the ones emitted by stimulators of evocated potentials [3].

In awake patients or with superficial sedation ocular movements create a slow recognizable activity. In BIS specific case, digitalized EEG is filtered to exclude artifacts of high and low frequencies and divided in epochs of two seconds. Each epoch is correlated with an Electrocardiogram (ECG) model and in case pacemaker spicules or ECG signals are shown, the same will be eliminated and lost data will be estimated by interpolation. Eyeball movements are detected and epochs contaminated with this artifact, discarded. Subsequently, the baseline is analyzed and contaminating voltages are eliminated due to low frequencies (for instance, low-frequency noise of electrodes) [3].

A BIS monitor provides a continuous display of the current BIS and several parameters important to BIS monitoring. The BIS is displayed in the upper left corner of the monitor. This score ranges from 0 to 100 and is a measure of cerebral electrical activity [4].

A score of 90 to 100 correlates with an awake state, scores in the 70 s to $80 \mathrm{~s}$ with conscious sedation, scores in the 60s to 70 s with deep sedation, and scores from the 40s to 60s with general anesthesia. A single-channel raw EEG tracing can be continuously displayed. The Signal-Qualityindex (SQI) bar indicates the reliability of the signal; the higher the SQI, the more reliable is the BIS displayed. The Electromyographic (EMG) bar indicates EMG activity, which reflects muscle stimulation and can be caused by anything that increases muscle tone or results in muscle movement. Some of the major causes of increased EMG on a BIS monitor are motor activity, pain, seizure activity, eye movement, and poor electrode contact. The higher the EMG activity, the lower is the reliability of the BIS. The trend part of the screen displays the history of various parameters [5].

In patients suffering from Traumatic Brain Injuries (TBI), It is important to monitor the state of consciousness in order to determine the modes of care, treatment and prognosis. Currently, Glasgow Coma Scale (GCS), which has been criticized for inefficiency is the most common tool for meas- urement of level of consciousness. It was found that BIS value significantly correlates with GCS value in adults with acute brain injury. As a continuous, real-time and objective parameter, BIS can be used as a new tool to assess and monitor the severity of brain injury [6].

Despite the significant correlation between GCS and BIS scores, the quantities of coefficient of correlation and coefficient of determination were low. Moreover, variability among BIS scores according to each specified value of GCS makes the use of this score difficult for monitoring the level of consciousness in TBI [6,7].

\section{Patients and Methods}

The study has been approved by the Department of Anaesthesia at Kasr El-Aini Hospital, Cairo University and the Local Ethics and Research Committee. Written informed consent was obtained from the relatives of each patient before operation.

This study had enrolled 40 patients with moderate to severe isolated head injury admitted to emergency room at Cairo University Hospital, in 2014 and 2015.

Inclusion criteria: Patients with ASA physical status I or II with age from 16 to 65 years old, having isolated head injury with Glasgow coma scale 12 or less.

Exclusion criteria: Patient with ASA III and IV, patients younger than 16 years old, patients older than 65 , patients with history of epilepsy, patients with Glasgow coma scale more than 12, patients with polytrauma.

\section{Methods:}

- Patients were examined for Glasgow Coma Scale at time of arrival, immediately after surgical intervention, after 3 days and after 2 weeks.

- Bispectral index was measured exactly after measuring Glasgow Coma Scale at time of arrival, immediately post-operative, after 3 days and after 2 weeks by another observer who doesn't know the measurement of Glasgow Coma Scale.

\section{Statistical analysis:}

Data were coded and entered using the statistical package SPSS Version 22. Kolmogorov-Smirnov test was used to evaluate data normality. Correlation between BIS and GCS scores was evaluated by using Spearman's correlation test. A $p$-value $<0.05$ was considered statistically significant. 


\section{Results}

Demographic data analysis:

Demographic data analysis including sex, age, type of injury. There were 29 male and 11 female patients. There were 10 patients with acute subdural hematoma, 24 patients with extradural hematoma, one patient with gunshot to the head and 5 patient with intracerebral hematoma.

Upon comparing the correlation between GCS and BIS readings, there was a strong correlation between GCS and BIS readings, correlation coefficient was 0.956 and $p$-value was $<0.001$.

Table (1): Patients' sex and type of trauma data.

\begin{tabular}{lll}
\hline & Count & $\%$ \\
\hline Sex: & & \\
F & 11 & 27.5 \\
M & 29 & 72.5 \\
& & \\
Type of injury: & 10 & 25 \\
Acute subdural hematoma & 24 & 60.0 \\
Extradural hematoma & 1 & 2.5 \\
Gunshot to head & 5 & 12.5 \\
Intracerebral hematoma & & \\
\hline
\end{tabular}

Table (2): Correlation between GCS and BIS.

\begin{tabular}{ll}
\hline & GCS \\
\hline$B I S:$ & \\
Correlation coefficient & .956 \\
$p$-value & $<0.001$ \\
$\mathrm{~N}$ & 157 \\
\hline
\end{tabular}

$\mathrm{N}$ : Number of relations.

\section{Discussion}

The BIS has been widely used in operating theaters to measure the hypnotic effects of anesthesia drugs $[7,8]$. Lately, its use is expanding in ICU for assessing consciousness level in sedated patients and also to predict the neurological outcome in brain-injured patients, along with auditory evoked potentials, EEG, and Somatosensory Evoked Potentials (SSEPs) [7,9].

This study was designed to determine the correlation between GCS level and BIS scores. It was found that BIS scores showed strong significant correlation with GCS level.

Correlation coefficient was 0.956 and $p$-value $\leq 0.001$.

This result is as same as the results of Jung et al., [8] and Schankers et al., [6] .
Jung et al., [7] showed that in 89 patients, the BIS was found to be significantly correlated with the level of consciousness, the BIS values increased with an increasing level of consciousness. Mean BIS values of coma, semicoma, stupor and drowsiness were $0.14 \pm 0.23,38.9 \pm 18.0,60.3 \pm 14.5$, and $73.6 \pm 16.5$, respectively.

Schankers et al., [6] is a multi-centric prospective study, 43 patients were included in the analyses. BIS showed a higher correlation with behavioral scales as compared to other EEG parameters. Moreover, BIS values differentiated levels of consciousness and distinguished VS from MCS while other EEG parameters did not. Finally, higher BIS values were found in patients who recovered at 1 year post-insult as compared to patients who did not recover.

\section{Conclusion:}

BIS value is highly correlated with GCS score in traumatic head inury patients. Further studies are needed to expect if certain Bispectral values can predict certain glasgow coma scale measurements.

\section{References}

1- RAMPILL I.J.: A primer for EEG signal processing in anesthesia. Anesthesiology, 89: 980-1002, 1998.

2- JOHANSEN J.W.: Update on bispectral index monitoring. Best Pract. Res. Clin. Anaesthesiol., 20: 81-99, 2006.

3- SILVA F.L. and NIEDERMEYER E.: Electroencephalography, 4th Edition, Philadelphia, Lippincott Williams \& Wilkins, 781-96, 1999.

4- PUNJASAWADWONG Y., PHONGCHIEWBOON A. and BUNCHUNGMONGKOL N.: "Bispectral index for improving anaesthetic delivery and postoperative recovery". The Cochrane Database of Systematic Reviews: CD003843, 2014.

5- MELANIE E. GELFAND, RODNEY. GABRIEL, ROBERT GIMLICH, et al.: Practice patterns in the intraoperative use of bispectral index monitoring J. Clinical monitoring Computing, 31 (2): 281-9, 2017.

6- SCHNAKERS C., LEDOUX D. and MAJERUS S.: Diagnostic and prognostic use of bispectral index in coma, vegetative state and related disorders Brain Injury, November, 22 (12): 926-31, 2008.

7- JUNG J.Y., CHO C.B. and MIN B.M.: "Bispectral index monitoring correlates with the level of consciousness in brain injured patients". Korean J. Anesthesiol., 64 (3): 246-50, 2013.

8- DOU L., GAO H., LU L. and CHANG W.: Bispectral index in predicting the prognosis of patients with coma in intensive care unit. World J. Emerg. Med., 5 (1): 536, 2014.

9- MENON D.K., SCHWAB K., WRIGHT D.W. and MAAS A.I.: Position statement: definition of traumatic brain injury. Arch. Phys. Med. Rehabil., 91: 1637-40, 2010. 


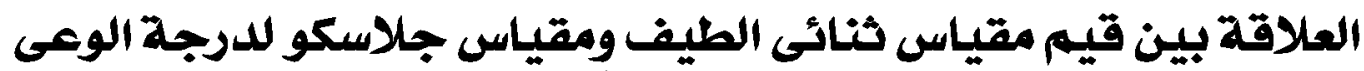

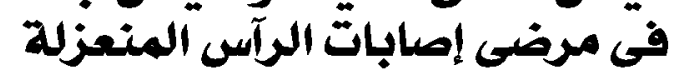

إستخدام مقياس ثنائى الطيف بفاعلية لتحديد درجة عمق التخدير إلا آنه مؤخرا ظهرت بعض الدراسات التى تحاول آن شبت فعاليته كذلك فى تحديد درجة الوعى.

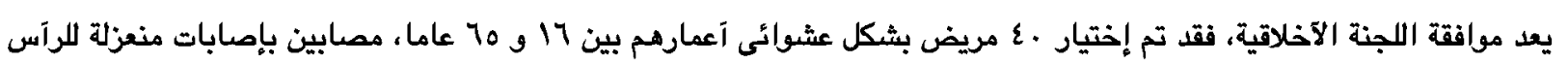
متوسطة آو حادة وتحتاج لتخل جراحى. تم قياس معامل جلاسكو للغييوبة عند وصول المريض ومباشرة بعد التدخل الجراحى وبعد ثلاثة آيام وبعد آسبوعين. كذلك تم آخذ قراءات معامل ثنائى الطيف مباشرة عقب قياس معامل جلاسجو اللغييوبة عند وصول المريض ومباشرة بعد التخخل الجراحى وبعد ثلاثة آيام وبعد آسبوعين.

وقد تم وجدنا آنه كان هناك علاقة وثيقة بين معامل جلاسجو للغييوية وبين قراءات معامل ثنائى الطيف. حيث كان معامل الإرتباط 907 هو . وهو ما كان له دلالة إحصائية. 